\title{
Sintering Properties of Iron Ore Mixes Containing Titanium
}

\author{
Neil John BRISTOW and Chin Eng LOO \\ BHP Research Newcastle Laboratories, BHP Co., Ltd., PO Box 188, Wallsend, NSW 2287, Australia.
}

(Received on December 24, 1991; accepted in final form on April 24, 1992)

\begin{abstract}
Titanium containing compounds are valuable materials for addition to the blast furnace to extend operational campaigns. However, the addition of these materials via the sinter plant has been known to create problems. This study investigates the effect of adding a titanomagnetite to two sintering ore blends, containing 10 and $20 \%$ pisolitic limonite respectively. The addition of up to $2 \%$ titanomagnetite did not affect the sintering parameters or sinter quality. Increasing the titanomagnetite levels to greater than $3 \%$ also had no significant influence on sintering but a significant deterioration in sinter RDI was recorded. Results also showed that the deterioration in RDI was greater for the blend containing more pisolitic limonite.

SEM studies carried out on the product sinters found most of the titanium in the glass phase. The mechanical properties of the glass was characterised using indentation fracture mechanics. Although some difficult was experienced, due to the small and disperse nature of the glass, addition studies using artifically manufactured glass indicated that the fracture toughness of the glass decreased with increasing titanium levels. It is postulated that because glass in the weakest phase in sinter and is widely dispersed any reduction in its fracture toughness will increase the vulnerability of the sinter to crack propagation, thereby increasing sinter RDI. It is also postulated that increasing the pisolitic level increased melt formation and the dispersion of the glass phase, resulting in a further deterioration in sinter RDI.
\end{abstract}

KEY WORDS: titanomagnetite; glass; sinter properties; RDI; fracture mechanics; titanium.

\section{Introduction}

Titanium-bearing minerals are commonly introduced into blast furnaces to protect the hearth and, consequently, extended operating campaign life. ${ }^{1,2)}$ The mechanism whereby this is achieved is thought to involve the formation of complex titano carbonitrides, of very high melting points, which precipitate out in the cooler areas of the hearth, i.e. areas with greatest heat loss, as additional refractory. ${ }^{3-5)}$

Generally, the amount of titanium added would depend on the condition of the hearth. Typical values would be between 4 and $7 \mathrm{~kg}$ per tonne of hot metal, but levels of up to $20 \mathrm{~kg}$ per tonne have been used in blast furnaces with severe hearth problems. Studies have shown that only the titanium present in the hot metal would react with the carbon and nitrogen to form the complex titanocarbonitrides. The added titanium would partition itself between the slag and the hot metal, with higher levels in the hot metal at low titanium additions. ${ }^{6)}$ These are a number of titanium containing materials that can be used as a source of titanium for the blast furnace. The main ones are ilmenite and, titanomagnetites and Sorel flux. The two natural materials are generally available as beneficiated products and, consequently, have fine particle size distributions. Unlike Sorel flux which is usually charged directly into the blast furnace, the most appropriate method of introducing ilmenite and titanomagnetites would be via the sinter plant, as a sinter mix component, rather than as a separately prepared agglomerate. Titanomagnetites have an advantage over ilmenite in that they contain significant iron units.

\section{The Effect of Titanium on Ore Sintering}

A survey of the literature in the area shows that relevant papers could be conveniently classified into two area: the sintering of titanomagnetites en masse, and the introduction of titanium bearing minerals (includes titanomagnetites) in limited quantities into a high chemical grade ore blend for the sole purpose of protecting blast furnace hearth.

In Eastern Europe and the Peoples' Republic of China, there are considerable reserves of titanomagnetites, many of which also contain high levels of vanadium. The ores are used in the local iron and steel industry and the common agglomeration techniques of sintering and pelletising are used to prepare the fines. The titanium content of the sinters produced can be very high, generally in the region of $12 \%$. As can be expected, the raw materials used in these reported studies are very different and it is not possible to derive quantitative relationships on the influence of sinter titanium content. However, there appears to be general agreement that increasing the level of titanium in the sinter mix reduced productivity,$^{7-11)}$ lowered sinter strength ${ }^{12,13)}$ and resulted in a deterioration in sinter reducibility. ${ }^{9,11,13)}$ It appears that some of these problems could be solved by increasing coke rate and increasing sinter basicity. ${ }^{7,9,11,12)}$

In the second area of introducing titania specifically 
for blast furnace hearth protection there is not a great deal of information in the open literature. General experience at BHP's Slab and Plate Products Division (SPPD) has indicated that the low temperature reduction degradation properties (RDI) of sinter were very dependent on sinter titania level: for every $0.1 \%$ increase in $\mathrm{TiO}_{2}$, sinter JSM RDI increased by $2.5 \%$. By way of illustration, at around August 1987, increasing the sinter $\mathrm{TiO}_{2}$ content from 0.12 to $0.35 \%$ using ilmenite sand increased RDI from about 38 to over $43 \%$. The increase in RDI was also observed to depend on the ore blend. The introduction of a $10 \%$ pisolitic limonite into the blend, at a comparable sinter $\mathrm{TiO}_{2}$ level of $0.35 \%$, resulted in the RDI increasing to around $45 \%$. As this value was unacceptable, ilmenite was removed from the ore mix; the sinter RDI immediately returned to the original value of $38 \%$. On a subsequent pile it was decided to confirm the observed dependence of RDI on $\mathrm{TiO}_{2}$ and pisolitic limonite levels. This time, at a sinter $\mathrm{TiO}_{2}$ level of $0.33 \%$ and a pisolitic limonite level of $5 \%$ in the blend, the sinter RDI was found to be $42.5 \%$. On removing the ore and ilmenite from the blend the sinter RDI immediately returned to the original value of $38 \%$. Other researchers ${ }^{2,14)}$ have also observed such a relationship between $\mathrm{TiO}_{2}$ and RDI.

The source of titanium was also found to influence $\mathrm{TiO}_{2}$ levels in the SPPD sinters, and, therefore, sinter RDI. For example, in early 1989, the condition of the No. 5 blast furnace (blow-in December 1978) hearth required the use of titanium. Initially, curushed concrete blocks made with ilmenite sand were used, followed by Sorel flux at a later stage. Whilst these materials had the desired effect of stabilising and increasing the furnace hearth refractory, the dust produced on charging to the furnace reported to the flue dust, and, consequently, into the sinter via the blended feed. It was observed that the use of crushed screened blocks of ilmenite sand produced more dust than Sorel flux, and this had the direct effect of increasing the titania level in the sinters produced.

Two techniques have been found to be effective in counteracting the increase in RDI at SPPD. The first involved increasing coke rates to raise sinter $\mathrm{FeO}$, which has also been suggested by other studies ${ }^{7,13,15)}$ and, the second, the introduction of silica sand into the sinter mix. Both had the effect of increased coke rates: the first directly and the other becase of the increased use of dolomite to replace serpentine in order to obtain a constant sinter silica content. The second countermeasure also had the added disadvantage of lowering sinter plant productivity, primarily through the increased use of dolomite.

\section{Laboratory Studies}

The present study was initated to examine the effect of introducing Taharoa ironsand from New Zealand into two ore blends of chemical compositions fairly typical of those seen in the Asia Pacific region. The blends, denoted by Blends 1 and 2, contained ores from Australia, Brazil and India and the chemical compositions of these
Table 1. Chemical composition of ores used in study.

\begin{tabular}{lcccccccc}
\hline Ore & $\mathrm{A}$ & $\mathrm{B}$ & $\mathrm{C}$ & $\mathrm{D}$ & $\mathrm{E}$ & $\mathrm{F}$ & $\mathrm{G}$ & $\mathrm{H}$ \\
\hline $\mathrm{Fe}_{t}$ & 62.2 & 63.6 & 63.3 & 61.6 & 57.6 & 68.3 & 68.2 & 67.2 \\
$\mathrm{SiO}_{2}$ & 5.61 & 4.36 & 3.35 & 7.77 & 5.31 & 0.63 & 0.63 & 2.64 \\
$\mathrm{Al}_{2} \mathrm{O}_{3}$ & 2.32 & 1.95 & 1.98 & 1.87 & 2.33 & 0.53 & 0.52 & 0.44 \\
$\mathrm{CaO}$ & 0.21 & 0.07 & 0.08 & 0.065 & 0.02 & 0.03 & 0.03 & 0.04 \\
$\mathrm{MgO}$ & 0.20 & 0.09 & 0.06 & 0.03 & 0.034 & 0.029 & 0.037 & 0.013 \\
$\mathrm{TiO}_{2}$ & 0.10 & 0.07 & 0.04 & 0.10 & 0.10 & 0.27 & 0.11 & 0.03 \\
$\mathrm{P}$ & 0.059 & 0.058 & 0.05 & 0.03 & 0.034 & 0.029 & 0.02 & 0.027 \\
$\mathrm{LOI}$ & 2.5 & 2.2 & 3.3 & 1.85 & 9.5 & 0.5 & 1.1 & 0.15 \\
\hline
\end{tabular}

Table 2. Base ore blends used in study.

\begin{tabular}{ccc}
\hline Ore & Blend 1 (\%) & Blend 2(\%) \\
\hline A & 28 & 23 \\
B & 7 & 7 \\
C & 12 & 7 \\
D & 5 & 5 \\
E & 10 & 20 \\
F & 15 & 15 \\
G & 13 & 13 \\
H & 10 & 10 \\
\hline
\end{tabular}

Table 3. Chemical composition and size distribution of Taharoa ironsand.

\begin{tabular}{lc}
\hline $\mathrm{Fe}_{\mathrm{t}}$ & 56.6 \\
\hline $\mathrm{FeO}$ & 26.5 \\
$\mathrm{SiO}_{2}$ & 4.17 \\
$\mathrm{Al}_{2} \mathrm{O}_{3}$ & 3.7 \\
$\mathrm{CaO}$ & 1.54 \\
$\mathrm{MgO}$ & 3.49 \\
$\mathrm{TiO}_{2}$ & 7.7 \\
$\mathrm{P}$ & 0.15 \\
$\mathrm{~K}_{2} \mathrm{O}$ & 0.072 \\
$\mathrm{Zn}$ & 0.076 \\
$\mathrm{LOI}$ & -2.9 \\
\hline
\end{tabular}

\begin{tabular}{lc}
\hline Sizing $(\mu \mathrm{m})$ & $\begin{array}{c}\% \text { retained } \\
\text { on screen }\end{array}$ \\
\hline+300 & 0 \\
$-300+212$ & 9 \\
$-212+150$ & 31 \\
$-150+125$ & 33 \\
$-125+106$ & 21 \\
$-106+75$ & 5 \\
-75 & 1 \\
\hline
\end{tabular}

ores are given in Table 1. A pisolitic limonite was used at a level of $10 \%$ in Blend 1 . To determine if a higher level of pisolitic limonite produced a further deterioration in sinter RDI the level of pisolitic limonite was increased to $20 \%$ for Blend 2 . The composition of the two blends are given in Table 2.

The Taharoa ironsand used in this study had a topsize of $0.3 \mathrm{~mm}$ and contained $7.7 \% \mathrm{TiO}_{2}$; the full size and chemical analyses are given in Table $\mathbf{3}$. The ironsand was added into the two blends as a diluent, of up to $6 \%$ on an ore basis. Sintering studies were carried out using the pilot scale sintering facility at the Newcastle Laboratories. ${ }^{16)}$ The sintering conditions used are summarised in Table 4. Limestone and serpentine were used to source the required basicity $\left(\mathrm{CaO} / \mathrm{SiO}_{2}\right)$ and $\mathrm{MgO}$ levels, of 1.6 and $1.5 \%$, respectively.

To obtain a target mix moisture for the sinter testwork, the effect of mix moisture on green bed permeability was examined for the two base Blends i.e., no ironsand addition. A standard procedure which involved $5 \mathrm{~kg}$ of a sinter mix was used. Granulation was carried out in a $0.25 \mathrm{~m}$ diameter drum and the granulated mix was then transferred into a cylindrical pot of $0.1 \mathrm{~m}$ diameter. For 
a standard material bed height of $500 \mathrm{~mm}$, compressed air was introduced to the top of the sealed pot. Air flow through the bed was determined at two pressure drop values across the bed. Figure 1 shows the results for Blend 1. Based on previous laboratory experience the optimum moisture for the sinter mixes was considered to be around $85 \%$ of the maximum air flow value (obtained from the permeability curves in Fig. 1). This equated to an optimum moisture content of $5.2 \%$ for the base Blend.

The size distribution of the ironsand indicates that during granulation all particles would report to the adhering fines layer of a pseudo-particle or granule. ${ }^{17,18)}$ This suggests that the addition of ironsand would improve granulation, leading to improved green bed permeability and sinter productivity. However, as the levels of ironsand considered in this study were less than $7 \%$, it was unlikely to significantly influence the response of the mix to granulation. It was therefore decided that the target mix moisture for blends containing ironsand would be similar to their respective base mixes.

The mixes for sintering were granulated in a $1 \mathrm{~m}$ diameter drum. After granulation, all the material was changed into the sinter pot, of grate area $0.09 \mathrm{~m}^{2}$ and ignited by means of a direct flame impingement burner. After an ignition period of $2 \mathrm{~min}$ under low suction, the burner was removed and the suction increased to $16 \mathrm{kPa}$ for the remainder of the test. The waste gas temperature was monitored continuously and the time interval between the start of ignition and the maximum waste gas temperature was taken as the sintering time.

The sinter was allowed to cool in the pot and then subjected to a standard shatter treatment followed by

Table 4. Summary of sintering test conditions.

\begin{tabular}{lc}
\hline Preparation & \\
Granulation time & $10 \mathrm{~min}$ \\
Charging & \\
Sintering grate area & $0.09 \mathrm{~m}^{2}$ \\
Bed height & $500 \mathrm{~mm}$ \\
Hearth layer & $30 \mathrm{~mm}$ \\
Sintering conditions & $120 \mathrm{~s}$ \\
Ignition time & $1250^{\circ} \mathrm{C}$ \\
Ignition temperature & $6 \mathrm{kPa}$ \\
Ignition suction & $16 \mathrm{kPa}$ \\
Sintering suction & downdraft \\
Cooling/Shatter & 4 drops from $2 \mathrm{~m}$ \\
\hline Cooling & \\
\hline
\end{tabular}

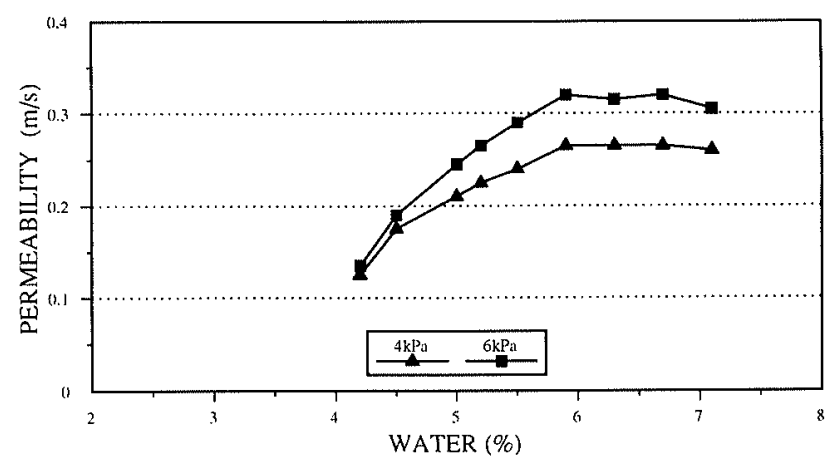

Fig. 1. Air flow rate as a function of mix moisture for of base Blend 1. screening. The return fines balance (ratio of return fines mass in the sinter mix to the mass of minus $6.4 \mathrm{~mm}$ sinter produced by the shatter treatment) was determined and only tests with a ratio between 0.95 and 1.05 were considered acceptable. The other criteria that had to be met in the testwork was sinter strength. Based on comparative studies carried out between full-scale plant and the laboratory unit it was considered that the sinter produced should have an ISO tumble index of $62 \pm 2 \%$ plus $6.4 \mathrm{~mm}$. On obtaining an acceptable test, a duplicate was carried out and the two sets of results are presented in this paper. In almost every case the two sets of results were closely comparable. Relevant sized sinter fractions were then removed for JIS reducibility and JSM reduction degradation (RDI) characterisation. For reducibility, duplicate tests were carried out, while for RDI between 3 and 6 tests were done depending on the scatter of the results. The averaged value from each test is reported.

\section{Results}

\subsection{Blend 1}

Figure 2 shows the effect of increasing the level of ironsand on sinter properties. Figure 2(a) shows that the introduction of ironsand did not have a significant influence on productivity; the variations seen were well within experimental error. The sinters containing ironsand appeared to have tumble strengths which were towards the upper range of the target mean value of $62 \%$ (Fig. 2(b)). In spite of the increase in tumble
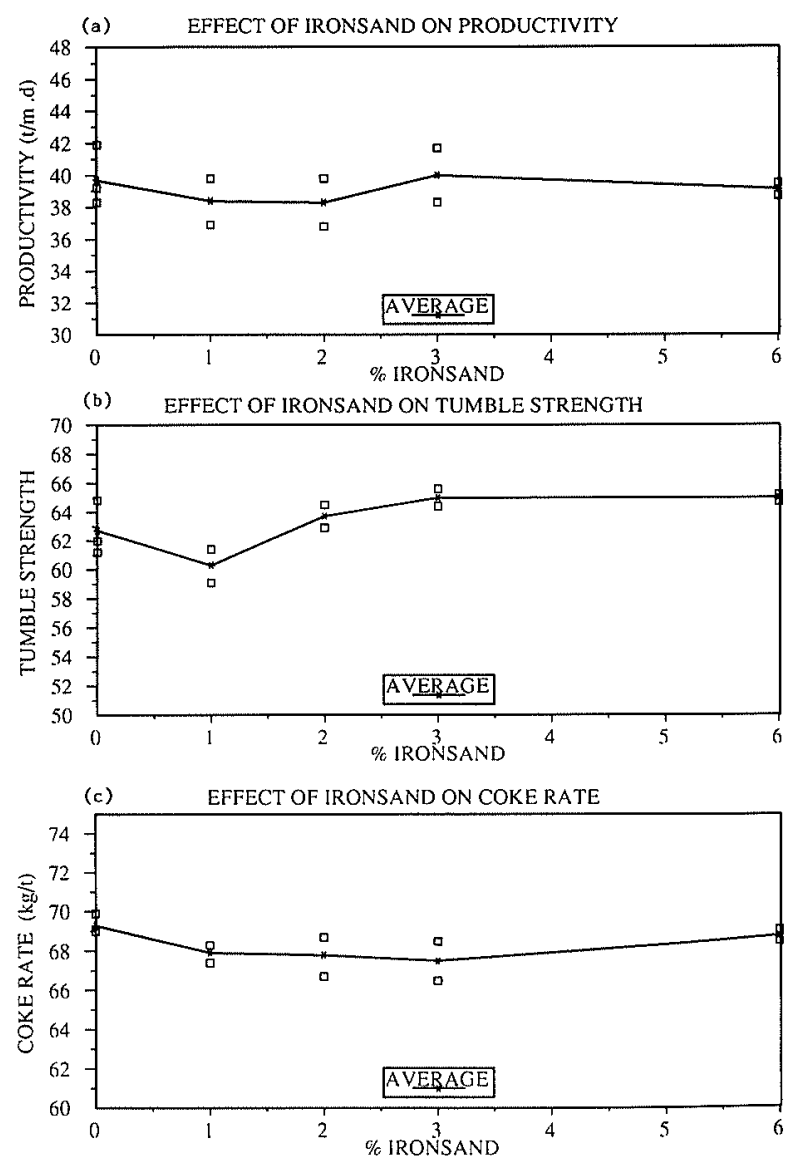

Fig. 2. The effect of ironsand on sintering for Blend $\mathrm{l}$. 

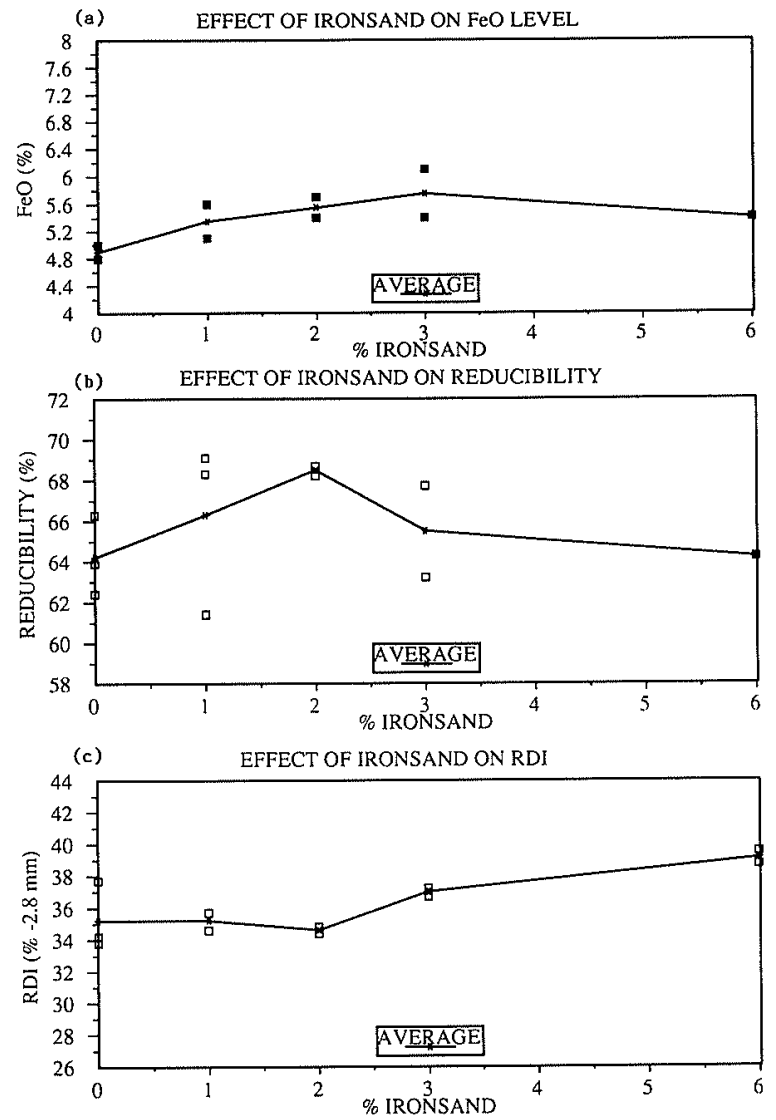

Fig. 3. The effect of ironsand on sinter quality for Blend 1 .

strength, no significant increases in coke rates were recorded. In fact, there appeared to be a drop in coke rate with ironsand addition although the decrease was not particularly significant (Fig. 2(c)). The improvement in sinter strength and reduction in coke rate could come about because of the oxidation of the titanomagnetites during sintering. The observed changes in strength and coke rates were only small-compatible with the low levels of ironsand added.

Figure 3 shows the effect of ironsand on sinter quality. The increase in sinter $\mathrm{FeO}$ with increased ironsand addition (Fig. 3(a)), could come about because part of the added titanomagnetite had not oxidised during sintering and/or because of higher sintering temperatures since the magnetite oxidation reaction is exothermic. Figure 3 (b) shows that the increased $\mathrm{FeO}$ levels did not have a very significant influence on reducibility which were in the region of $66 \pm 2 \% R$ for all the sinters. There did not appear to be any definite trend between ironsand level and reducibility. Figure 3(c) shows that for RDI, there was a trend of increasing values for ironsand levels of greater than $2 \%$. The 5 percentage point change in RDI from 35 to 39 for 2 to $6 \%$ ironsand in the mix was significant. Generally, for a particular sinter mix, as $\mathrm{FeO}$ increases RDI would decrease. The results indicate that the small quantity of ironsand had a significant influence on the sintering of the (predominantly) hematite ore blend.

\subsection{Blend 2}

For this particular Blend only the base case and the
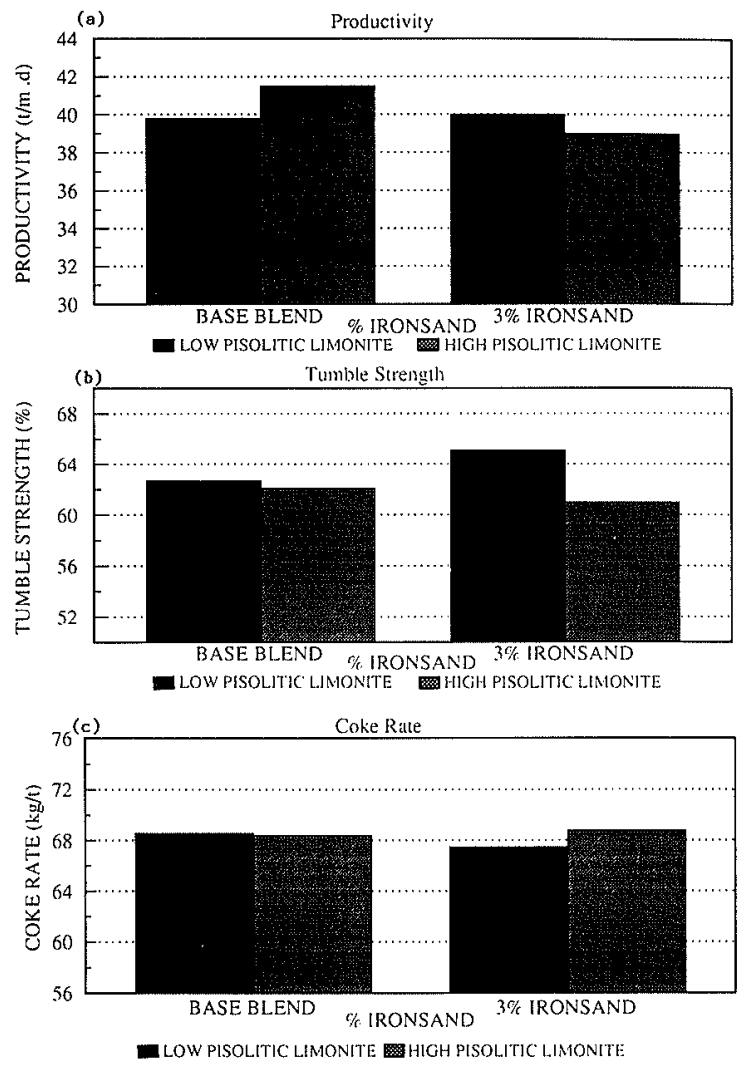

Fig. 4. The effect of ironsand on sintering for Blend 2.

blend with $3 \%$ ironsand addition was considered. To determine the influence of higher levels of pisolitic limonite, the results for Blend 1 at 0 and $3 \%$ ironsand would be used for comparison. Figure 4 shows the results for the two base blends and the two blends with $3 \%$ ironsand.

Figure 4(a) shows that the productivity for the four blends ranged between 39 and $41.5 \mathrm{t} / \mathrm{m}^{2} /$ day. As such the differences in productivity between the blends were not very significant. Perhaps, the only surprising result is that the base blend which contained $20 \%$ pisolitic limonite, a highly fusible ore, gave a marginally higher productivity value than the base blend with $10 \%$ pisolitic limonite. (It is generally considered that because pisolitic limonites are a very fusible ores, increasing their levels in a blend would lower productivity.) For Blend 2 the addition of $3 \%$ ironsand resulted in a slight loss in strength (Fig. 4(b)). Although this may not be significant, it is nevertheless interesting to note that the trend seen for Blend 1, of increasing strength with ironsand addition, was not observed for Blend 2. Likewise, the trend of lowering coke rate obtained for Blend 1 at increasing ironsand level was not seen for Blend 2 .

The sinter quality results given in Fig. 5 show that for both the blends sinter $\mathrm{FeO}$ were higher with ironsand addition. However, for Blend 2 there was a significant drop in reducibility and the deterioration in sinter RDI was much more severe with the introduction of $3 \%$ ironsand.

\section{Cause of Deterioration in RDI}

The test results indicate that the trends obtained in 

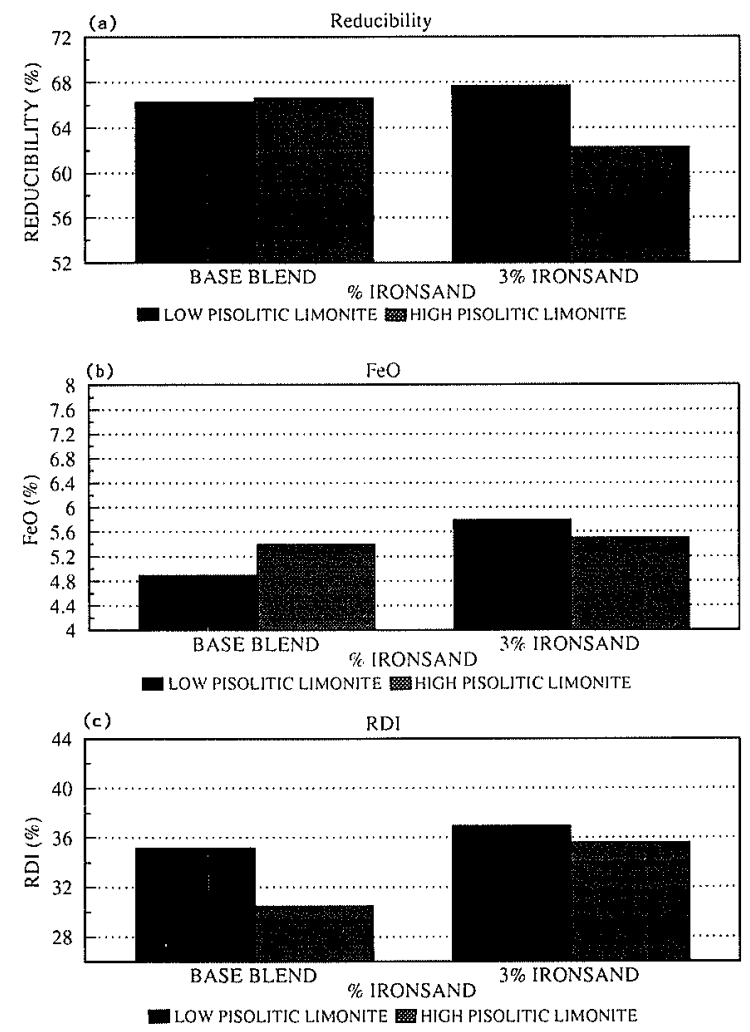

Fig. 5. The effect of ironsand on sinter quality for Blend 2 .

the laboratory using titanomagnetites are similar to those observed at the BHP SPPD plant with Sorel flux and ilmenite. Regardless of source, the major influence of $\mathrm{TiO}_{2}$ is on sinter RDI, and the deterioration in RDI is more severe in the presence of higher levels of pisolitic limonite. To understand the link between RDI and sinter $\mathrm{TiO}_{2}$, samples of sinter, crushed to minus $2 \mathrm{~mm}$ but generating minimum fines levels, were set in resin and polished for mineral composition determination using a standard manual point-counting technique. Larger pieces of sinter, of around $10 \mathrm{~mm}$, were also prepared using the same technique for SEM-EDAX study.

Figure 6 shows the sinter mineralogy results for Blend 1. The primary hematite results show an initial drop in value followed by a levelling off. The magnetite results are almost a mirror image of the primary hematite results, showing that a significant increase in magnetite content only occurred from 0 to $1 \%$ ironsand. From the sinter $\mathrm{FeO}$ values, it is not surprising that ironsand addition resulted in an increase in the magnetite content. Both the secondary hematite and SFCA levels also increased with ironsand addition, while the composition of glass in the sinters is very comparable.

For this study the ironsand was added a diluent into the iron ore blend. As most of the ore components are coarse (minus $6 \mathrm{~mm}$ ) hematites, it is not surprising that mixes with ironsand had lower primary hematite contents. At between 2 and $6 \%$ ironsand addition, the primary hematite content remained virtually constant even through the hematite content in the mix decreased; this could arise because of the preferential melting of the fine ironsand. Basically, the mineral contents of the sinters with $1,2,3$ and $6 \%$ ironsand are not very dis-

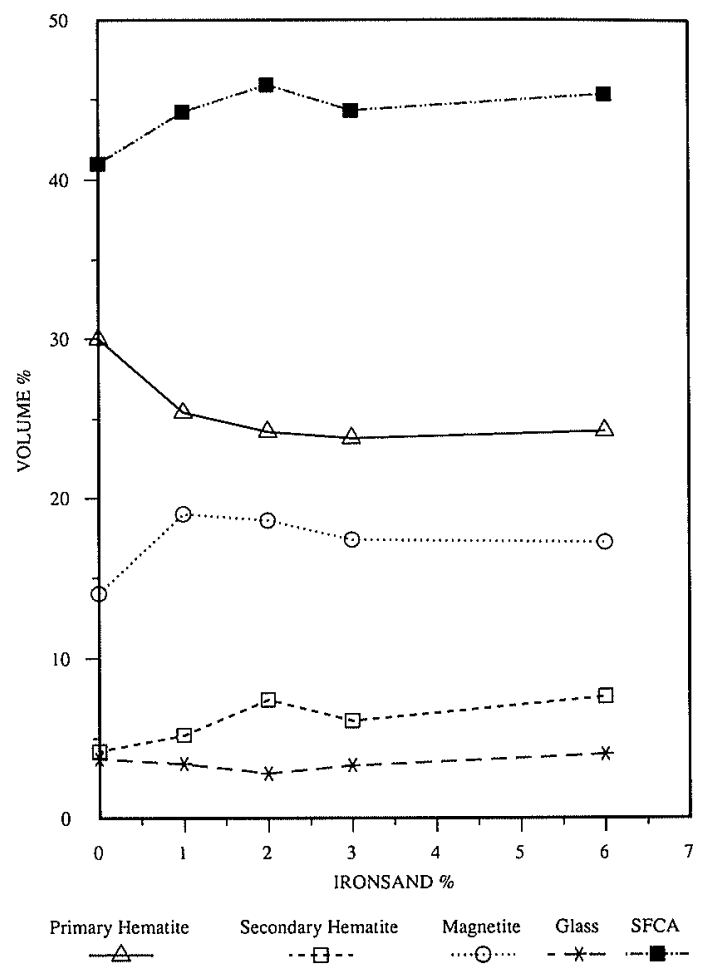

Fig. 6. Mineralogy of sinters produced from Blend 2 .

similar. The comparative levels of secondary hematite and SFCA (which contains only the $\mathrm{Fe}^{3+}$ ion $^{19)}$ ) in the sinters would suggest that as the proportion of titanomagnetites is increased a corresponding increase in titanomagnetite oxidation is obtained.

The reasonably comparable mineralogy results obtained for the sinters with between 1 to $6 \%$ ironsand would indicate that the changes in RDI observed in Fig. 3 were not a direct result of changes in sinter mineral composition. It is also unlikely that the morphology of the mineral phases could influence the RDI. Studies have shown that a certain form of secondary hematite, i.e., skeletal rhombohedral hematite ${ }^{20)}$ has very detrimental effect on RDI. For all the sinters manufactured in this study only trace levels of this form of hematite were found. This is not entirely surprising since productivity, flame front speed and, consequently cooling rates (it was shown that the formation of skeletal rhombohedral hematite was very dependent on cooling rates ${ }^{20}$ ) were very comparable for all the tests.

EDAX analysis of the mounted sinter pieces was carried out to determine the titanium contents of the phases, and the results are given in Fig. 7. As the fluxes and iron ores used contain traces of $\mathrm{TiO}_{2}$, very low levels of $\mathrm{TiO}_{2}$ were detected in base Blend 1 , most of which were found in the glass phase. As the addition of titanomagnetite was increased to $6 \%$ the $\mathrm{TiO}_{2}$ content of the glass increased appreciably reaching levels of over $4 \%$. Other exsolution phases were also found to contain titanium. The $\mathrm{TiO}_{2}$ content of secondary hematite and SFCA also increased with increasing ironsand addition, but the increases were very much smaller in magnitude compared to those obtained for glass.

Based on sinter mineral composition and EDAX analysis, the deterioration in RDI was most likely the 


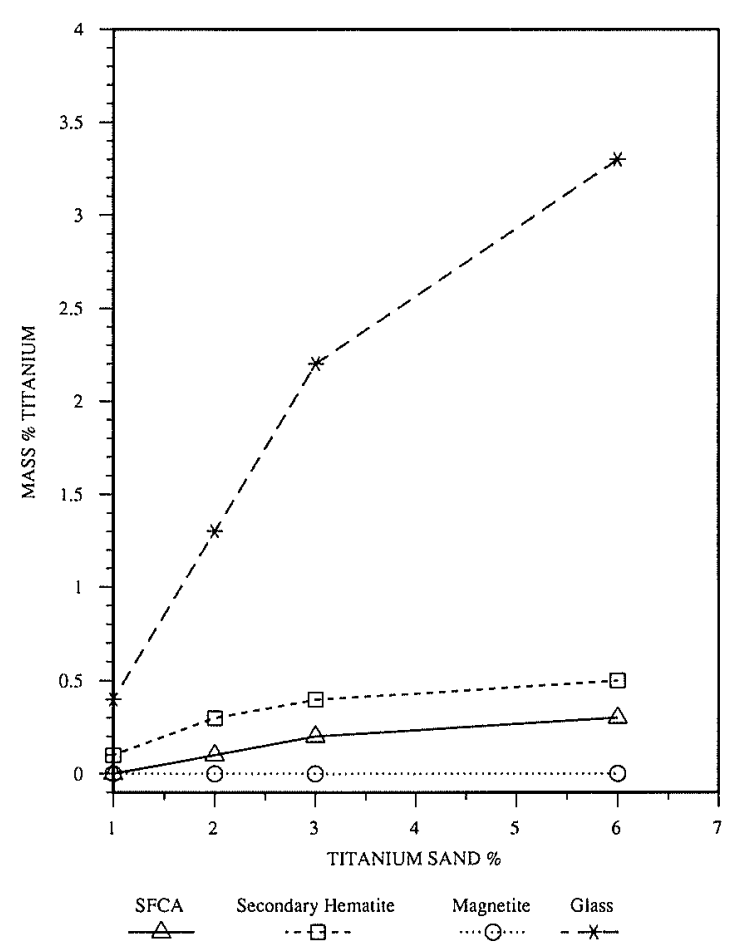

Fig. 7. Levels of titanium in sinter phases for Blend 1.

result of increased level of titania in the glass. For example, $\mathrm{TiO}_{2}$ could lower the mechanical strength of glass which, in turn, enhanced the crack propagation process during the low temperature reduction test. This concept was put forward by Loo et al. ${ }^{21)}$ and they also showed that glass had the lowest fracture toughness compared to the other phase present in sinter i.e., most vulnerable to crack propagation. Limited mineralogical studies carried out using Blend 2 also indicated that the level of glass in the sinters were comparable to those seen for the Blend 1 sinters i.e., between 3 and $4 \%$. However, the level of secondary (exsolution) phases was higher because of the increased formation of melt. It is possible that this resulted in a further deterioration in RDI for the following reason. During the cooling cycle in sintering, glass is virtually the last phase to solidify and contains all the remnant oxides in solution. An increase in the amount of melt, as in Blend 2, would mean that the glass was distributed over a much wider area of the sinter structure, resulting in increased vulnerability to crack propagation.

With a view to test the above hypothesis and to understanding the relationship between the mechanical properties of glass containing $\mathrm{TiO}_{2}$ and sinter RDI, a fracture mechanics approach was adopted, as used in an earlier study. ${ }^{21)}$

\section{Fracture Toughness Determination Using Indentation Techniques}

When sufficient force is applied to a Vickers indenter as it enters a flat surface, an inverted pyramid shaped indentation with 4 radial cracks will form in the material. The fracture toughness of a material, $K_{1 \mathrm{c}}$, is determined from the following equation:

$$
K_{1 \mathrm{c}}=C(E / H)\left(L / c^{3 / 2}\right)
$$

where $C$ is a material independent constant, $L$ is the load, $H$ is the Vickers Hardness, $E$ is the elastic modulus, and $c$ is the crack length. ${ }^{21)}$ Basically at constant load, increasing $(E / H)$ ratio at constant crack length would mean a tougher material, while materials with constant $(E / H)$ values could vary in toughness depending on the crack length. Hardness and crack length were determined using a Vickers indenter while a Knoop indenter was used to measure elastic modulus. During indentation, a plastic/elastic field is formed to induce cracking and for this reason the above equation includes the hardness and elastic modulus of the material. A detailed description of the two indenters and the principles whereby these material parameters are determined have been given. ${ }^{21)}$

Sinter is polyphase material manufactured by a thermal process. Because the phases have dissimilar properties e.g. thermal expansion coefficient, residual stresses and cracks would be present in sinter. It is most likely that the strength of a sinter could be a function of the propensity of these cracks to propagate across the different mineral phases i.e. dependent on the fracture toughness of the phases. Fracture toughness is probably the most important parameter determining the physical breakdown of sinter structure. Hardness provides a measure of the plasicity of the material and hard materials are usually brittle, but, like the elasiticity modulus, it does not provide a measure of the material's resistance to physical breakdown.

The use of indentation techniques to form cracks and characterise the vulnerability of mineral phases to crack propagation, has been reported by a number of workers. ${ }^{22-24)}$ However, these studies only determined crack length. As crack length is a function of indentation technique, fracture toughness is a more appropriate measure of the propensity of a material to fail by crack propagation. During an RDI test fines are generated because of increased crack formation, resulting from the reduction of hematite, and the propagation of cracks across the sinter mineral phases. The latter is probably the more important of the two because sinters already contain substantial cracks. Further, physical breakdown of the material does not occur if the cracks are arrested e.g., in the tougher mineral phases. For this reason, it has been shown that the fracture toughness of the mineral phases have a significant influence on sinter RDI. ${ }^{21}$

\section{Fracture Toughness of Glass Containing Titania}

In heterogeneous sinters, glass is usually present in small pools or around the periphery of exsolution crystals or mineral grains. For these laboratory sinters, particular problems were encountered as the glass pools present were very randomly distributed and varied considerably in size. In many cases, glass pools were found very near to pores and were not large enough to accommodate an indentation with well-defined radial cracks. Indentation studies were therefore carried out over a very large number of areas in a sample. This could create problems as glass, being the last phase to solidify on cooling, would be expected to have very variable chemical and physical properties e.g. thickness. Figure 8 shows a typical glass 


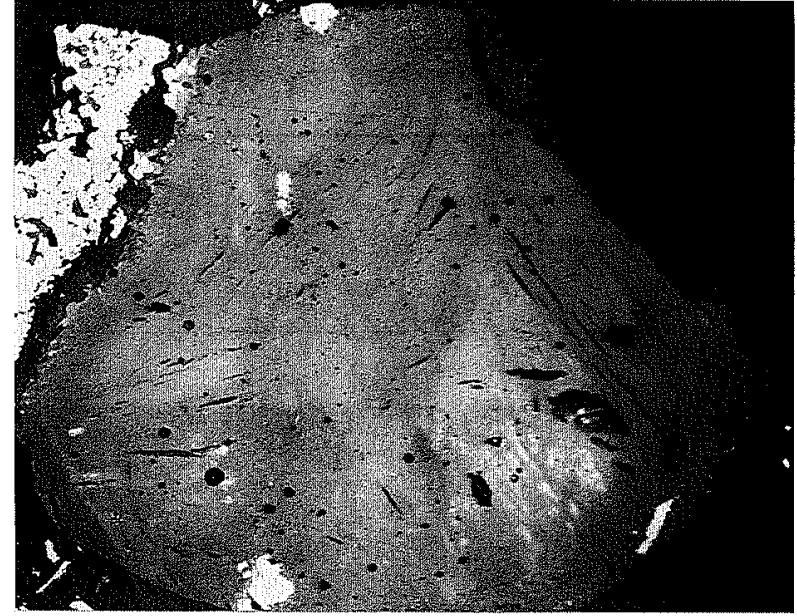

Fig. 8. Photograph of typical glass pool in the sinters.

Table 5. Vickers indentation data for ironsand sinters.

\begin{tabular}{crrrrr}
\hline & \multicolumn{5}{c}{ Ironsand level (\%) } \\
\cline { 2 - 6 } & Base & \multicolumn{1}{c}{1} & 2 & 3 & $6 \%$ \\
\hline Hardness $(\mathrm{GPa})$ & 6.97 & 6.94 & 6.98 & 7.19 & 7.14 \\
Std. deviation & 0.33 & 0.30 & 0.29 & 0.30 & 0.26 \\
\hline Crack length $(\mu \mathrm{m})$ & 11.6 & 12.8 & 11.8 & 10.9 & 11.6 \\
Std. deviation & 1.9 & 2.0 & 1.5 & 1.1 & 1.6 \\
\hline
\end{tabular}

Results are averages for around 50 measurements.

area in these sinters.

In this study, it was found that loads higher than those used in the previous study on plant sinters, were required to form cracks and the reproducibility of the results was also poorer. Although larger errors were associated with hardness values, the values obtained at 3 and $6 \%$ ironsand addition were significantly higher. Crack length results, based on selective indentations in large glass pools showed no change with increased $\mathrm{TiO}_{2}$ content of the glass. The elastic modulus results obtained from Knoop indentations were found to be very variable and no apparent trends were observed. Table 5 shows the mean results for $H$ and $c$ together with standard deviations. The standard deviations indicate that no firm conclusions can be drawn about the effect of sinter $\mathrm{TiO}_{2}$ level. The wide range in results possibly reflected the variability in chemical composition of the glass and the fact that the measurements were carried out over a large number of areas. Ideally to determine $K_{1 \mathrm{c}}$ both the Vickers and Knoop indentations should be carried out in the same glass pool. In many instances it was not possible to find pools of glass of sufficient size to accommodate both indentations.

In an attempt to improve the reproducibility of the results, a microindentation technique capable of measuring $\mathrm{H}$ and $\mathrm{E}$ from a single indent, was used to quantify the properties of the glass. The instrument (UMIS 2000 Ultra-Micro Indentation System), developed by the $\overline{C S I R} \overline{\mathrm{O}}$, utilises a different principle to determine $\mathrm{E}$ and $\mathrm{H}$. In the UMIS, as the indenter enters the surface, the penetration depth obtained as a function

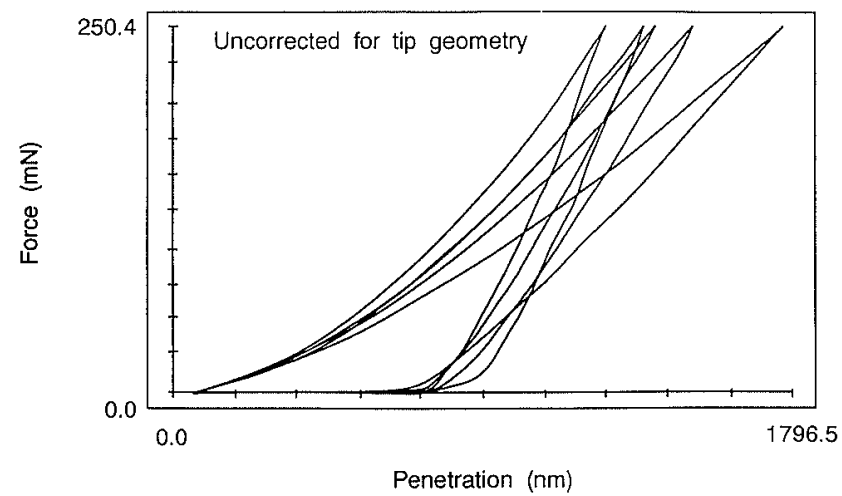

Fig. 9. UMIS results for the glass phase showing the loading and unloading behavior of the indenter.

Table 6. Hardness and elastic modulus results obtained using UMIS.

\begin{tabular}{ccc}
\hline Glass pool & $H(\mathrm{GPa})$ & $E(\mathrm{GPa})$ \\
\hline 1 & 11.6 & 122.4 \\
2 & 11.5 & 112.3 \\
3 & 11.3 & 99.6 \\
\hline
\end{tabular}

of force is recorded and used to determine hardness. As the indenter withdraws from the surface during unloading, the deformed area will not alter for a fullyplastic material, but for a fully-elastic material there will be complete recovery i.e., the loading and unloading curves would be identical. For most materials the two curves would be displaced and the elastic modulus can be determined from the gradient of the linear portion of the downward sloping section of the unloading curve using Sneddon's analysis. ${ }^{25)}$

With the UMIS, loads required to generate cracks, were found to be typically 60 to $80 \mathrm{~g}$. However, crack lengths were very irregular and suggested that there may be appreciable internal stresses in the glass phases. There were also indications that many of the glass phases were thin and the indentation was affected by the underlying substrate. At a load of $2.5 \mathrm{~g}$, it was found that although $H$ values were reproducible, $E$ values showed a high degree of scatter, even though measurements were carried out on the same piece of sinter. Figure 9 shows loading and unloading curves for the same sample and it is evident that the plastic depth and therefore the hardness is approximately constant but that the elastic modulus varied noticeably. Table 6 shows $H$ and $E$ values for a piece of sinter made using Blend 1 with $3 \%$ ironsand. These results are typical of those found for sinters produced using different ironsand levels.

The hardness values obtained using UMIS were substantially higher than those shown in Table 5. This is because the UMIS system uses a Birkovich indenter rather than a Vickers indenter. The Birkovich indenter has a triangle-based pyramid while the Vickers indenter is a square-based pyramid. This difference in geometry has been shown to result in different hardness values.

The variation in $E$ can possibly be ascribed to differences in compliance during measurements. Because glass is a hard material and is spread out thinly, the 


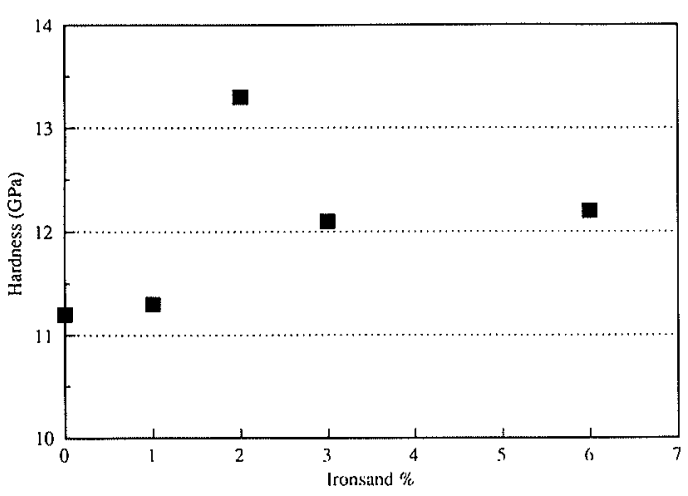

Fig. 10. Hardness values of glass at a load of $25 \mathrm{mN}$.

Table 7. Chemical composition of artificial glass phases.

\begin{tabular}{lccccc}
\hline & $\mathrm{Fe}_{2} \mathrm{O}_{3}$ & $\mathrm{SiO}_{2}$ & $\mathrm{Al}_{2} \mathrm{O}_{3}$ & $\mathrm{CaO}$ & $\mathrm{TiO}_{2}$ \\
\hline Base & 17.0 & 38.5 & 4.0 & 40.5 & 0.0 \\
$\mathrm{TiO}_{2}$ glass & 17.0 & 37.5 & 4.0 & 39.5 & 2.0 \\
\hline
\end{tabular}

response of the surrounding phases (particularly, the underlying material) become significant when the indenter withdraws from the surface. The machine compliance would also contribute towards the total compliance of the system but this is likely to be constant.

At very low loads of $25 \mathrm{mN}$, indentation results showed a trend of increasing $H$ with increasing titania level, Fig. 10. However, the results for $E$ were still very variable. When it became clear that reliable crack lengths and $E$ could not be obtained, a decision was made to produce artificial glasses of similar chemical compositions i.e., based on EDAX results, for indentation studies. Mixtures containing different $\mathrm{TiO}_{2}$ levels (Table 7) were produced using laboratory grade chemicals and heated in a Ulvac-Riko Infrared furnace under conditions similar to those found in sintering. ${ }^{26)}$ Unfortunately, the sintered product was not a glassy but di-calcium silicate powder, which had undergone the phase transition between $\beta$ and $\gamma$. Attempts at overcoming this phase transition by altering the thermal cycle proved unsuccessful.

It is likely that artificial glass could not be produced because the EDAX-measured chemical compositions, as shown in Table 7, were not accurate. EDAX gives an average chemical composition of the area in the path of the electron beam, and the beam is also capable of penetrating a few microns into the surface. In particular because glass has a low density the penetration of the electron beam would be greater compared to a dense phase e.g., secondary hematite, which means that a thin glass layer could result in more of the underlying substrate being included in the analysis. The other problem with EDAX is the difficulty in focusing the beam only onto the small glass pools; this can also result in inaccuracies. However, there is no doubt that the glass phase has the highest titania level. The results for secondary hematite and SFCA, given is Fig. 7 were carried out in large areas where the surrounding phases would not interfere with the EDAX beam. As interference was only obtained for glass, it is most likely that the
Table 8. Chemical composition of titania containing glasses.

\begin{tabular}{lrrr}
\hline \multicolumn{1}{c}{$\mathrm{Mix}$} & 1 & 2 & \multicolumn{1}{c}{3} \\
\hline $\mathrm{SiO}_{2}$ & 58.3 & 56.6 & 55.0 \\
$\mathrm{Al}_{2} \mathrm{O}_{3}$ & 4.6 & 4.5 & 4.3 \\
$\mathrm{CaCO}_{3}$ & 18.5 & 18.0 & 17.4 \\
$\mathrm{Kaolin}_{\mathrm{TiO}}$ & 18.5 & 18.0 & 17.4 \\
$\mathrm{TiO}_{2}$ & 0.0 & 2.9 & 5.7 \\
\hline
\end{tabular}

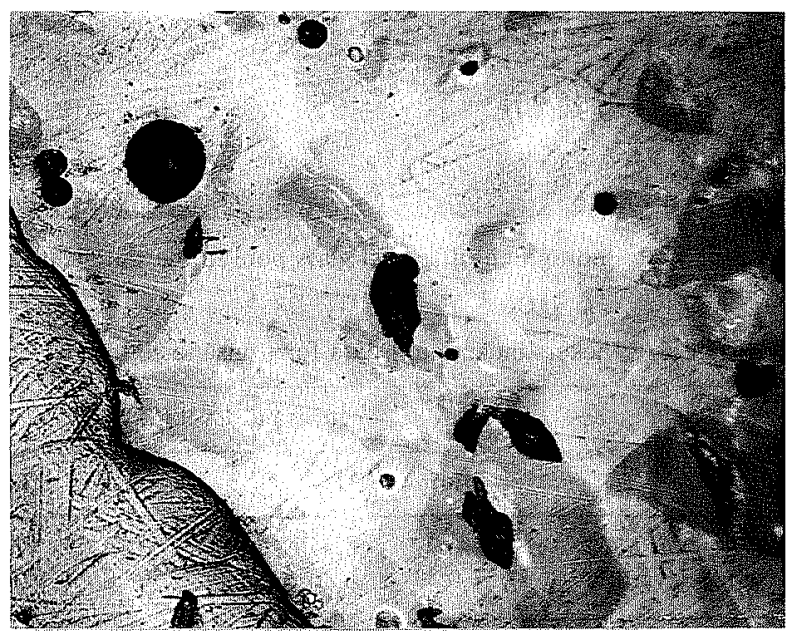

Fig. 11. Photograph of artificial glass.

Table 9. Hardness and elasticity values for artificial glass.

\begin{tabular}{lccc}
\hline Nominal $\mathrm{TiO}_{2}$ level $(\%)$ & 0 & 3 & 6 \\
Hardness $(\mathrm{GPa})$ & 6.25 & 6.53 & 8.72 \\
Elastic Modulus (GPa) & 13.9 & 12.0 & 12.2 \\
$E / H$ & 2.2 & 1.8 & 1.4 \\
\hline
\end{tabular}

titania levels in glass would be higher than the values indicated by Fig. 7 .

With a veiw to obtain some reliable data on fracture toughness for glass containing different levels of $\mathrm{TiO}_{2}$, a mix developed in the ceramic industry for producing glaze was used. $\mathrm{TiO}_{2}$ was added at two different levels and the chemical composition of the three mixes are shown in Table 8. Studies indicated that glass could be produced by heating the mixtures at $1500^{\circ} \mathrm{C}$ for $20 \mathrm{~min}$ followed by rapid cooling rapidly in air. Large pools of glass were produced (Fig. 11) which appeared to be more porous than those seen in sinters.

The earlier procedure using Vickers and Knoop indenters were used to determine $H, E$ and $K_{1 c}$. At loads of $100 \mathrm{~g}$ very reproducible $E$ and $H$ values were obtained and Table 9 shows that hardness increases with $\mathrm{TiO}_{2}$ content, resulting in a decrease in the $E / H$ ratio. However, a significant number of the cracks formed did not originate from the corners of the indentation possibly because of influence of the pores. Consequently a reliable fracture toughness value could not be obtained even though, in every case, results showed that crack lengths increased or remained the same with increasing $\mathrm{TiO}_{2}$, which would results in a decrease in $K_{1 \mathrm{c}}$. 


\section{Discussion}

\subsection{Toughness of Glass Containing Titania}

The resistance of a material to crack propagation is a function of its fracture toughness $K_{1 \mathrm{c}}$. The fracture toughness of a material such as glass would be a function of its chemical composition and crystal structure. As glass is the last phase to solidify it contains all the remnant oxides in solution; it is therefore not surprising that the mechanical properties of glass are variable. In addition, because glass is well dispersed between the exsolution phases it can play an important role in determining sinter degradation even though its volumetric proportion is only small. The presence of certain chemical species in the glass could alter its mechanical properties, and consequently have a significant influence on the degradation properties of the sinter.

This study has shown that during sintering titania in the mix selectively concentrates in the glass phase. Whilst it was not possible to show a decrease in fracture toughness with increased titania, and therefore provide conclusive proof that this was the cause of the increase in sinter RDI, evidence was available to support this hypothesis. Results indicate an increase in $H$ with little or no corresponding change in crack length. Although it was not possible to obtain $E$ values for the glass phases in the sinters, $E$ values of glassy materials was found to be independent of $\mathrm{TiO}_{2}$ levels. The increase in hardness together with unchanged values of crack length and elastic modulus would result in a lower fracture toughness value.

\subsection{Reduction Degradation Mechanism and the Role of Glass}

During a reduction degradation test, the initiation of deleterious cracks is caused by the stresses induced when hematite is reduced to magnetite. An examination of sinter which have been reduced (but not subjected to tumbling) suggests that these cracks then propagate opening up new areas and exposing hematite to the reducing gases. The reduction of hematite in the paths of these cracks generates more stresses which are then relieved by the further propagation of the crack. During an RDI test the weight loss during reduction is typically less than $1 \%$, suggesting that crack propagation is a very important mechanism influencing fines generation. It has been observed that sinters with very similar hematite contents can have very different RDI values, further suggesting that the propagation of cracks during reduction can be retarded by the other phases present. It is conceivable that even a slight reduction in the severity and rate of propagation can greatly reduce RDI because:

(1) as a result of reduced toughness of the surrounding phases and increased crack formation, new hematite areas will be exposed earlier,

(2) the reduction of these hematite areas will result in more stresses generated in the early stages of reduction,

(3) these stresses together with the reduced toughness of the surrounding bonding phases will cause very severe cracking of the structure, and

(4) this in turn opens up significantly incresed hematite areas to the reducing gases.

The increased reduction leading to increased crack propagation is a chain reaction which at the end of the reduction period has a significant cumulative effect on the number and severity of cracks formed in the sinter structure. At the end of reduction the material is tumbled. As the tumbling process is comparatively gentle, it is unlikely that it has any further detrimental effect on the overall sinter structure, except the fissuring of loosely held material.

As glass is widely dispersed among the other sinter bonding phases, it appears possible that a reduction in the toughness of glass can affect the degradation mechanism leading to higher sinter RDI. Increasing the level of a pisolitic limonite resulted in the formation of more melt during sintering, further increasing the dispersion of $\mathrm{TiO}_{2}$ containing glass in the sinter structure. This would have further increased the severity of crack propagation during reduction and result in even higher sinter RD1.

\subsection{Effect of Reducing the Toughness of Glass on Sinter Strength}

In the determination of tumble strength, the lifters in the drum would result in material being dropped from heights of not more than $0.5 \mathrm{~m}$ (the drum diameter is $1.0 \mathrm{~m}$ ). The stresses experienced by the internal regions of a sinter particle during dropping and abrasion in the drum would be very small compared to that obtained during an RDI test. For this reason during an RDI test there is major breakdown of the sinter structure i.e., fracturing of the sinter particles, but not during a tumble test. In a tumble test fines are mainly generated by the chipping of material from the surfaces of the sinter particles.

The sinter testwork showed that the formation of glass containing $\mathrm{TiO}_{2}$ did not have a significant effect on the tumble strength of the sinter products. This is not surprising since glass is not an important bonding phase in these sinters. If glass was the major bonding material e.g., in homogeneous sinters, then there would most likely be a corresponding deterioration in sinter strength as the toughness of the glass phase decreases.

As discussed, the mechanisms leading to material degradation during low-termperature reduction and strength determination are very different. Based on an understanding of the two mechanisms involved it appears that the toughness of the glass phase can have a very significant influence on RDI but not tumble strength - as indicated by the results.

\section{Conclusions}

Information from commercial plants indicate that when sinters are used to carry the titania required for blast furnace hearth protection, sinter RDI is adversely affected. The deterioration in RDI was found to be more severe in the presence of pisolitic limonite which is a highly fusible ore. These findings were based on the use of ilmenite and Sorel flux to source the titania. Laboratory studies indicated that the use of Taharoa ironsand, containing $7.7 \% \mathrm{TiO}_{2}$, showed a similar 
deterioration in RDI at high ironsand addition levels. Likewise, a blend containing a higher level of a pisolitic limonite resulted in a greater deterioration in RDI.

The laboratory studies also showed that the introduction of up to $6 \%$ ironsand did not affect productivity or coke rate. Slight increases in sinter strength were obtained, and sinter $\mathrm{FeO}$ increased, although this did not appear to have a significant effect on sinter reducibility. It appears that part of the titanomagnetite oxidized during sintering, resulting in higher levels of SFCA and secondary hematite.

SEM-EDAX studies carried out on the sinters indicated that increasing the level of ironsand addition greatly increased the titania content of the glass phase. For all the sinters the volume of glass present was comparable. It is postulated that the presence of titania lowered the mechanical strength of the glass resulting in a greater vulnerability to crack propagation which, in turn, resulted in deterioration in sinter RDI. Indentation studies, carried out to characterise the mechanical properties of the glass, showed that as its titania content increased, its hardness value also increased. Results also showed conclusively that the elastic modulus values were comparable regardless of the titania content. However, major problems were encountered in determining reliable crack lengths mainly because the glass pools were small and had highly variable chemical compositions. Limited results indicated that crack lengths did not decrease with titania addition. Additional studies using artificial glass also suggested that the fracture toughness of glass decreased as $\mathrm{TiO}_{2}$ is introduced into its structure.

\section{Acknowledgements}

The authors are grateful to New Zealand Steel for their financial support of the sintering programme and their permission to publish the results. We also acknowledge the contributions of Mr. B. England (SEM-EDAX), Ms J. Goss (indentation studies), and the CSIRO Division of Applied Physics for the use of UMIS. Finally, we would like to thank the management of BHP Steel SPPD for permission to use plant trial results and the management of BHP Research for permission to publish this paper.

\section{REFERENCES}

1) I. F. Carmichael and J. Lowering: Steel Times, 209 (1981), No. $8,416$.

2) G. T. Da Rocha, G. M. De Araujo and M. Braga: Metal. ABM, 41 (1985), No. 326, 25.

3) S. Zhang and Z. Yu: Ironmaking Proc., Vol. 47, ISS-AIME, Penn., (1988).

4) J. T. Chao: Rev. Metall., 86 (1989), No. 10, 765.

5) J. T. Chao, J. Cook and A. E. Grau: Ironmaking Proc., Vol. 48, ISS-AIME, Penn., (1989), 383.

6) A. Ledzki: Hutnik., 4 (1986), 95.

7) R. Budzki, W. Sabela, R. Stec, J. Mroz, T. Czarneki, J. Otreba and M. Zawodny: Hutnik, 55 (1988), No. 5, 146.

8) X. Li: Proc. Int. Symp. on Exploitation and Utilisation of Vanadium Bearing Titanomagnetite, Metall. Industry Press, Beijing, Nov., (1989), 351.

9) Q. Zuou and Y. Ren: Proc. Int. Symp. on Exploitation and Utilisation of Vanadium Bearing Titanomagnetite, Metall. Industry Press, Beijing, Nov., (1989), 322.

10) R. Benesch, M. Wyderko and A. Ledzki: Hutn. Listy, 42 (1987), No. 8, 533.

11) R. Budzik: Stal', 10 (1987), 8.

12) R. Budzki: Hutnik, 54 (1987), No. 5, 132.

13) R. Benesch, M. Wyderko-Delekta and A. Ledzki: Hutnik, 56 (1989), No. 5, 170.

14) R. Rochas, N. Dalla Corte and J. L. Gerbe: Ironmaking Proceedings, Vol. 44, ISS-AIME, Penn., (1985), 365.

15) R. Budzik and R. Stec: Hutmik, 52 (1985), No. 7, 230.

16) C. E. Loo: Ironmaking Steelmaking, 18 (1991), 33.

17) J. D. Litster, S. K. Nicol and A. G. Waters: Trans. Iron Steel Inst. Jpn., 26 (1986), 1036.

18) J. D. Litster, S. K. Nicol and A. G. Waters: ISIJ Int., 29 (1989), 274.

19) L. Yang, C. E. Loo and J. Ostwald: IMM Section C, 99 (1990), $\mathrm{C} 80$.

20) T. Inazumi, K. Shinada and M. Kawabe: Tetsu-to-Hagané, 68 (1982), 2207.

21) C. E. Loo, K. T. Wan and V. R. Howes: Ironmaking Steelmaking, 15, (1988), No. 6, 279.

22) N. Sakamoto, H. Fukuyo, Y. Iwata and T. Miyashita: Tetsu-to-Hagané, 70 (1984), 40.

23) N. Sakamoto, H. Fukuyo, Y. Iwata and T. Miyashita: Symp. Burden Design for Blast Furnaces, McMaster Univ., Hamilton, May, (1984).

24) I. Shigaki, M. Sawada and N. Gennai: Trans. Iron Steel Inst. $J p n ., 26$ (1986), 503.

25) I. N. Sneddon: Int. J. Eng. Sci., 3 (1965), 47.

26) N. J. Bristow and A. G. Waters: Trans. IMM Section C, 100 (1991), C1. 